\title{
A New Technique for Minimizing Cervical Trauma and Enhancing Surgical Performance in Gynecological Procedures Requiring Cervical Dilatation
}

Ayman S. Dawood ${ }^{1, *}$ and Mohamed A. Raslan ${ }^{2}$

${ }^{1}$ Lecturer of Obstetrics and Gynecology, Tanta University, Egypt

${ }^{2}$ Assistant Lecturer of Obstetrics and Gynecology, Tanta University, Egypt

\begin{abstract}
Objectives: To minimize cervical trauma, enhance performance and reduce complications during gynecological operations requiring cervical dilatations.
\end{abstract}

Patients and methods: This study was conducted on 200 women in child bearing age scheduled for operative hysteroscopy for a variety of conditions as infertility or abnormal uterine bleeding. Patients were randomly allocated into two groups according to method of cervical traction. Cervical stitch for patients in group I $(n=100)$, while using vulsellum in group II $(n=100)$. This study was done at Tanta University Hospitals in the period from October 1, 2015 to September 30, 2016. All demographic data, operative type, cervical trauma, operative bleeding or cervical lacerations were gathered and analyzed.

Results: All patients' demographic data were statistically non-significant in the studied groups. The operative time required for cervical dilatation was shortened in group I (10.66 \pm 2.70 minutes) compared to $(18.2 \pm 1.45$ minutes) with $\mathrm{P}$ value $=0.02$. No complications occurred in group I while bleeding occurred in group II due to excessive force against the vulsellum with multiple applications and slipping of the vulsellum leading to more lacerations and more bleeding. Additional measures were used in group II only to stop or minimize complications.

Conclusions: Cervical stitch applied before gynecological procedures requiring cervical dilatation was more effective and helpful than vulsellum use and was not associated with any cervical trauma, lacerations, or bleeding.

\section{Introduction}

Cervical dilatation is mandatory before a many gynecological operations as uterine biopsy, operative hysteroscopy, and loop insertion. By far operative hysteroscopy is the most common gynecologic operation requiring cervical dilatation up to $10 \mathrm{~mm}$ with multiple insertions and extractions of the operative system. The diameter of the hysteroscope is generally too large to easily pass through the cervix directly, thereby necessitating cervical dilation to be performed prior to its insertion. Cervical dilation can be performed by temporarily stretching the cervix with a series of dilators of increasing diameter $[1,2]$.

Difficulty in cervical dilatation is a complication that is infrequently discussed, despite the fact that almost $50 \%$ of hysteroscopic complications are related to difficulty with cervical entry. Potential complications include cervical tears, creation of a false passage, perforation, bleeding, or simply difficulty in entering the internal os with the hysteroscope $[3,4]$.

Many trials were made to facilitate cervical dilatation including preparation of cervix by misoprostol or lamineria tents or balloon catheter given the night prior to procedure. Although these methods were successful in many patients giving little time and effort in cervical dilatation, but these methods were not adequately effective in patients with previous cesarean deliveries and cervical fibrosis or stenosis. Cervical stenosis remains an obstacle for safe hysteroscopic procedures as it requires more time, effort and associated with many complications as cervical lacerations, bleeding or potential cancellation of the procedure [5-8].

Repeated trials of dilatations with vulsellum either single toothed or multiple toothed are associated with cervical trauma, bleeding, surgical team exhaustion and potential cancellation of the procedure.
Vulsellum with relatively large diameter points on the grasping portion frequently cause traumatic bleeding and may require suturing to stop the bleeding. Also, excessive traction on application can pull off cervical tissue causing lacerations and more bleeding. Cervical infections may follow the use of a vulsellum because the vulsellum pierces and compresses the cervix. Moreover considerable cramping and discomfort are often experienced when vulsellum was applied in awake patients $[9,10,11]$.

From these drawbacks we developed a new technique similar to cerclage by applying a nylon or silk suture at the external os to serve as a stable, steady element for traction on the cervix preventing repeated applications and slipping of vulsellum. At the end of procedure the stitch can be removed easily by traction or scissor.

\section{Materials and methods}

Study design and settings: A prospective randomized controlled study conducted at Tanta University Hospitals in the period from October 1, 2015 to September 30, 2016.

Patients: The enrolled 200 patients were randomly allocated into 2 groups. Group I included 100 patients with application of cervical stitch. Group II included 100 patients with application of traditional

"Corresponding Author: Dr. Ayman Shehata Dawood, Department of Obstetrics and Gynecology, Faculty of Medicine,Tanta University, Tanta-31111, Egypt; E-mail: ayman.dawood@med.tanta.edu.eg

Citation: Dawood AS, Raslan MA (2017) A New Technique for Minimizing Cervical Trauma and Enhancing Surgical Performance in Gynecological Procedures Requiring Cervical Dilatation. Int J Gynecol Clin Pract 4: 126. doi: https://doi.org/10.15344/2394-4986/2017/126

Copyright: (c) 2017 Dawood et al. This is an open-access article distributed under the terms of the Creative Commons Attribution License, which permits unrestricted use, distribution, and reproduction in any medium, provided the original author and source are credited. 
Citation: Dawood AS, Raslan MA (2017) A New Technique for Minimizing Cervical Trauma and Enhancing Surgical Performance in Gynecological Procedures Requiring Cervical Dilatation. Int J Gynecol Clin Pract 4: 126. doi: https://doi.org/10.15344/2394-4986/2017/126

Page 2 of 4

vulsellum. Randomization was done by enclosed envelope method with alternate allocation.

Patients were included by the following inclusion criteria: (i) Age between 18 and 49 years, (ii) Patients suffering infertility with uterine lesions as submucous myomas or polyps, and (iii) Patients suffering abnormal uterine bleeding requiring curettage for obtaining biopsy and decreasing blood loss.

Preoperative: 2 tablets of misoprostol equal $400 \mu \mathrm{g}$ were inserted vaginally the night before procedure in all patients.

\section{Procedure}

In group I: The cervix was grasped by vulsellum and silk suture no. 1 was applied all around the cervix with 4 bites including cervical mucles in a manner similar to McDonald cerclage. The stitch was applied at $1 \mathrm{~cm}$ above the level of external os and stretched anteriorly with artery forceps to serve as traction in steed of the vulsellum Tightening of the stitch could be done easily when leakage of fluid occurred to raise intrauterine pressure improving performance and vision in operative hysteroscopy (Figure 1).

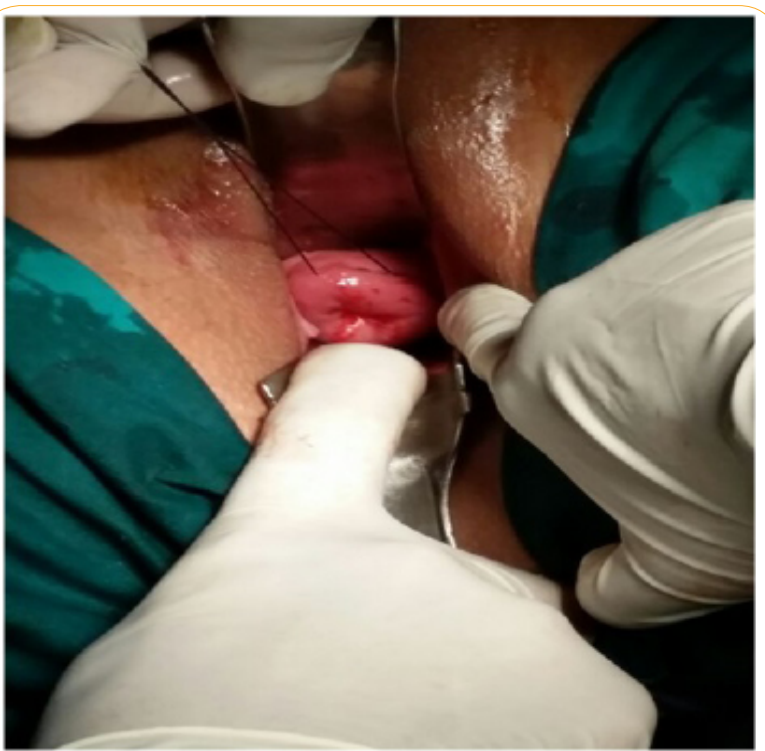

Figure 1: The cervical stitch in place before traction on the cervix.

In group II: The cervix was grasped by vulsellum till the end of procedure.

Methods: All demographic data, type of gynecological procedures, time for cervical dilatation and any complications occurred were recorded

\section{Outcomes of Study}

1-Time required to dilate the cervix to $10 \mathrm{~mm}$.

2-Intraoperative complications of the procedure including: cervical tears, creation of a false passage, or bleeding.

3-The need for additional measures or cancellation of procedures.

Ethical approval: The study was approved by local institutional ethics committee of Tanta University Hospitals.

Statistical methods: All data collected were analyzed by SPSS version 18. The tests used were mean, standard deviation, Chi square and $\mathrm{P}$-value less than 0.05 is considered significant.

\section{Results}

The enrolled patients were 200 patients allocated in 2 groups with equal number in each group (100 patients). The flow chart was shown in Figure 2.The demographic data of enrolled patients were shown in table 1.

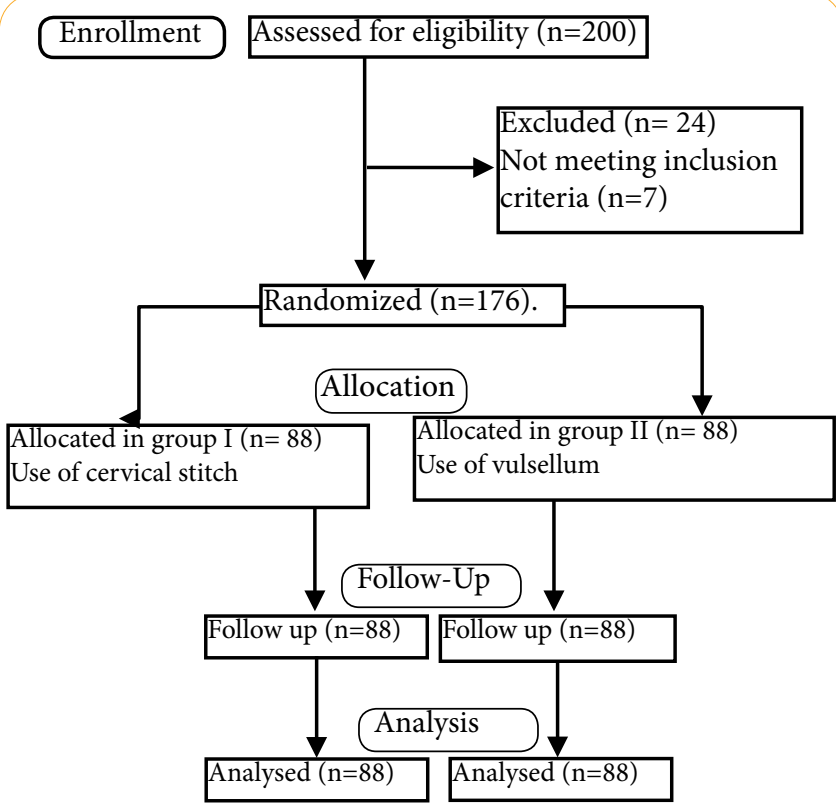

Figure 2: Flow chart of enrolled patients.

The mean age was $24.5 \pm 3.87$ years in group I and 25.6 \pm 3.21 years in group II with non-significant difference (P value 0.0233 ). There were no significant difference in gravidity, parity and BMI. The types of procedures were operative hysteroscopy in 144 patients and uterine biopsy for 32 patients (Table 1).

The mean time for cervical dilatation was $10.66 \pm 2.70$ minutes in group I while it was $18.2 \pm 1.45$ minutes with significant difference between both groups $(P$ value $=0.002)$. As regard operative complications, there were no cervical lacerations, or bleeding in group I while bleeding occurred in $12(13.64 \%)$ and lacerations of cervix occurred in 68 (77.27\%) in group II (Table 2$)$.

Lacerations and bleeding were managed by additional measures as suturing in 2 cases (2.27\%), coagulants were used in 58 cases $(65.91 \%)$ and vaginal packing was used in 34 cases $(38.64 \%)$. The cancellation occurredin 3 cases in group II due to cervical stenosis with multiple applications and slipping of the vulsellum and failure to reach $10 \mathrm{~mm}$ in dilatation resulting in exhaustion of medical staff and occurrence of false tracks (Table 2).

The most interesting data found was that sometimes the cervix was dilated excessively resulting in leakage of fluid from inside the uterus. In this situation the stitch was tightened over the scope in group I [8 cases $(9.09 \%)$ ] preventing leakage and improving performance and vision inside the uterus. In group II, this situation was reported in [ 6 cases $(6.82 \%)$ ] and was solved by application of another vulsellum with more traumas to the cervix (Table 2). 
Citation: Dawood AS, Raslan MA (2017) A New Technique for Minimizing Cervical Trauma and Enhancing Surgical Performance in Gynecological Procedures Requiring Cervical Dilatation. Int J Gynecol Clin Pract 4: 126. doi: https://doi.org/10.15344/2394-4986/2017/126

Page 3 of 4

\begin{tabular}{|l|l|l|l|l|}
\hline & $\begin{array}{l}\text { Group I } \\
\text { Cervical } \\
\text { stitch (n=88) }\end{array}$ & $\begin{array}{l}\text { Group II } \\
\text { Vulsellum } \\
(\mathrm{n}=88) \\
\text { Mean } \pm \text { SD }\end{array}$ & $\mathrm{X}^{2}$ & P value \\
\hline Age (years) & $24.5 \pm 3.87$ & $25.6 \pm 3.21$ & 2.23 & 0.233 \\
\hline Gravidity & $1.3 \pm 0.40$ & $1.7 \pm 0.45$ & 1.87 & 0.477 \\
\hline Parity & $1.6 \pm 0.32$ & $1.3 \pm 0.64$ & 1.35 & 0.068 \\
\hline BMI & $23 \pm 3.44$ & $22 \pm 2.98$ & 2.38 & 0.093 \\
\hline $\begin{array}{l}\text { Type of procedure } \\
\begin{array}{l}\text { Operative } \\
\text { hysteroscopy } \\
\text { Uterine biopsy } \\
\text { Table 1: The demographic data of enrolled patients. }\end{array}\end{array}$ & $\begin{array}{l}74(84.09 \%) \\
14(15.91 \%)\end{array}$ & $\begin{array}{l}70(79.55 \%) \\
18(20.45 \%)\end{array}$ & 3.404 & 0.386 \\
\hline
\end{tabular}

\begin{tabular}{|c|c|c|c|c|}
\hline & $\begin{array}{l}\text { Group I } \\
\text { Cervical } \\
\text { stitch } \\
(\mathrm{n}=88) \\
\text { Mean } \pm \text { SD }\end{array}$ & $\begin{array}{l}\text { Group II } \\
\text { Vulsellum } \\
(n=88) \\
\text { Mean } \pm \text { SD }\end{array}$ & $\mathrm{X}^{2}$ & $P$ value \\
\hline $\begin{array}{l}\text { Time of cervical } \\
\text { dilatation(minutes) }\end{array}$ & $10.66 \pm 2.70$ & $18.2 \pm 1.45$ & 2.415 & $0.002^{*}$ \\
\hline Leakage of fluid & $\begin{array}{l}\text { Tightening } \\
\text { of stitch } \\
\text { in } 8 \text { cases } \\
(9.09 \%)\end{array}$ & $\begin{array}{l}\text { Adding } \\
\text { another } \\
\text { vulsellum in } 6 \\
\text { cases }(6.82 \%)\end{array}$ & 2.34 & 0.190 \\
\hline \multicolumn{5}{|c|}{ Operative complications } \\
\hline Bleeding & $0(0.00 \%)$ & $12(13.64 \%)$ & $1 . .126$ & $1 . .126$ \\
\hline Cervical lacerations & $0(0.00 \%)$ & $68(77.27 \%)$ & 3.490 & 3.490 \\
\hline \multicolumn{5}{|c|}{ Use of additional measure } \\
\hline Suturing of bleeders & $0(0.00 \%)$ & $2(2.27 \%)$ & 1.022 & 1.022 \\
\hline Coagulants & $0(0.00 \%)$ & $58(65.91 \%)$ & 1.050 & 1.050 \\
\hline Vaginal Packing & $0(0.00 \%)$ & $34(38.64 \%)$ & 1.034 & 1.034 \\
\hline $\begin{array}{l}\text { Cancellation of } \\
\text { procedures }\end{array}$ & $0(0.00 \%)$ & $3(3.41 \%)$ & 1.003 & 1.003 \\
\hline
\end{tabular}

Table 2: The operative data in the studied groups.

\section{Discussion}

Cervical dilatation is the cornerstone in many gynecological procedures requiring introduction of sizable instruments inside the uterus. Many of these operations are done for biopsy in bleeding disorders or for exploring uterine cavity in infertility assessment. By far operative hysteroscopy is the most common gynecological operation requiring wide cervix and associated with multiple insertions and extractions of the scope [1,2].

Many interventions were tried to make dilatation easier as preliminary administration of lamineria tents or misoprostol to soften cervix. Difficulty and/or resistance to dilatations remain an important issue in some cases with stenosed cervix [3-8]

The most common type of cervical injury is a superficial laceration caused by the vulsellum or Allis forceps tearing off during dilation. At the other extreme are the cervico vaginal fistula and the longitudinal laceration ascending to the level of the uterine vessels. Rates of cervical injury range from 0.01 to 1.6 per 100 suction curettage $[12,13]$.
In the current study, a cervical stitch was applied to the cervix in a manner like cerclage but at $1 \mathrm{~cm}$ above level of external os aiming to apply traction on the cervix with single application in group I compared to the traditional use of cervical vulsellum in group II.

The demographic data were nearly the same in both groups. Operative time required for cervical dilatation was shortened in group I (10.66 \pm 2.70 minutes) compared to (18.2 \pm 1.45 minutes) with $P$ value (0.02). No complications occurred in group I while bleeding occurred in group II due to excessive force against the vulsellum with multiple applications and slipping of the vulsellum leading to more lacerations and more bleeding (Table 2).

Additional measures were taken in group II to decrease or stop bleeding as the use of by vicryl-1 suture to ligate bleeders which was indicated in 2 cases $(2.27 \%)$, coagulants were used in 58 cases $(65.91 \%)$ and vaginal packing were used in 34 cases (38.64\%) (Table 2).

No cancellation of procedures was reported in group I while in group II, 3 cases were cancelled due to tight cervical stenosis with multiple applications and slipping of the vulsellum, failure to reach $10 \mathrm{~mm}$ in cervical dilatation, tired exhausted medical staff and occurrence of false tracks Table 2

Johnson et al. (1991) conducted a study to evaluate safety of vulsellum use. They concluded that routine use of a vulsellum theoretically makes insertion of an intrauterine device safer and the passage of an embryo transfer catheter less traumatic [14].

Turok et al. conducted a study on 25 patients to evaluate Bioceptive cervical retractor instead of traditional vulsellum in IUD insertion. They concluded that the Bioceptive ${ }^{\infty}$ suction cervical retractor demonstrated a new trend toward lower pain scores than the singletooth vulsellum and is a viable, atraumatic alternative [15].

Another trial done in Utah University, USA to replace the traditional vulsellum by a new spiral cervical retractor apparatus to minimize cervical trauma and decrease pain score in most of gynecological procedures. They concluded that the new device is a good alternative to vulsellum and is considered a potent cervical retractor that causes minimal pain, bleeding and cramping [9].

\section{Conclusion}

The application of cervical stitch before gynecological procedures requiring wide cervical dilatation was more effective than vulsellum. It provided stable and steady element for traction on the cervix and could be tightened to prevent leakage of fluids from inside the uterus to improve vision and performance in operative hysteroscopy.

\section{Competing Interests}

The authors declare that they have no competing interests.

\section{Author Contributions}

Dr. Ayman Shehata Dawood: Is the idea developer, operating all cases, gathering information and revisions were done by him.

Dr. Mohamed Attia Raslan: Is the writer, data analyzer and revisions were done by him. 
Citation: Dawood AS, Raslan MA (2017) A New Technique for Minimizing Cervical Trauma and Enhancing Surgical Performance in Gynecological Procedures Requiring Cervical Dilatation. Int J Gynecol Clin Pract 4: 126. doi: https://doi.org/10.15344/2394-4986/2017/126

\section{References}

1. Bradley LD (2002) Complications in hysteroscopy: prevention, treatment, and legal risk. Curr Opin Obstet Gynecol 14: 409-415.

2. Guido R, Stovall D (2007) Hysteroscopy Version 14.3.

3. Laparoscopy and Hysteroscopy (2012) A Guide for Patients. From the American Society for Reproductive Medicine, Patient Education Committee.

4. Polyzos NP, Zavos A, Valachis A, Dragamestianos C, Blockeel C, et al. (2012) Misoprostol prior to hysteroscopy in premenopausal and postmenopausal women. A systematic review and meta-analysis. Human Reprod Update 18: 393-404.

5. Crane JM, Healey S (2006) Use of misoprostol before hysteroscopy: a systematic review. J ObstetGynaecol Can 28: 373-379.

6. Yu D, Li T-c, Xia E, Huang X (2006) A prospective, randomized controlled trial comparing vaginal misoprostol and osmotic dilator in achieving cervical ripening before operative hysteroscopy. Gynecological Surgery 3: 186-189.

7. Christianson MS, Barker MA, Lindheim SR (2008) Overcoming the challenging cervix: techniques to access the uterine cavity. J Low Genit Tract Dis 12: 24-31.

8. Batukan C, Ozgun MT, Ozcelik B, Aygen E, Sahin Y, et al. (2008) Cervical ripening before operative hysteroscopy in premenopausal women: a randomized, double-blind, placebo-controlled comparison of vaginal and oral misoprostol. Fertil Steril 89: 966-973.

9. Hatasaka HH, Crangle R (2003) Spiral cervical retractor apparatus.

10. Byron Masterson (2012) Manual of Gynecologic Surgery. 2nd edition. pp 44-45.

11. Doty N, Maclsaac L (2015) Effect of an atraumaticvulsellum versus a singletooth vulsellumon pain perception during intrauterine device insertion: A randomized controlled trial. Contraception 92: 567-571.

12. Lohr PA, Hayes JL, Gemzell-Danielsson K (2008) Surgical versus medical methods for second trimester induced abortion.

13. Haskell WM, Easterling TR, and Lichtenberg ET (1999) Surgical abortion after the first trimester. In Paul M, Lichtenberg ES, and Borgatta L (eds): A Clinician's Guide to Medical and Surgical Abortion. New York: Churchill Livingstone, pp. 123-138

14. Johnson N, Bromham DR (1991) Effect of cervical traction with a vulsellum on the uterocervical angle. Br J Obstet Gynaecol 98: 309-312.

15. Turok DK, Cappiello B, Sanders JN, Thompson I, Storck K, Gawron LM (2015)A novel atraumatic alternative to the cervical vulsellum: a randomized controlled trial comparing the Bioceptive ${ }^{\circledR}$ suction cervical retractor with single-tooth vulsellum during IUD insertion. Contraception 92: 406-406. 